\title{
Morbidity and Mortality Patterns among Neurological Patients in the Intensive Care Unit of a Tertiary Health Facility
}

\author{
O. P. Adudu ${ }^{1}$, O. A. Ogunrin ${ }^{2}$, and O. G. Adudu ${ }^{3}$ \\ ${ }^{1}$ Department of Anaesthesiology, College of Medical Sciences, University of Benin, Benin City, Edo State, \\ Nigeria \\ ${ }^{2}$ Department of Medicine, College of Medical Sciences, University of Benin, Benin City, Edo State, Nigeria \\ ${ }^{3}$ General Hospital, Ogwashi Uku, Delta State, Nigeria \\ Reprint requests to: DR. O.P. Adudu, P.O.Box 4254, Benin City, Edo State, Nigeria. \\ E-mail:opadudu@yahoo.com
}

\begin{abstract}
Background/Objective: The morbidity and mortality of neurological patients managed in the intensive care unit reflect the causes of neurological disorders and the effectiveness of management.

Method: The morbidity and mortality patterns of neurological patients admitted into the intensive care unit of the University of Benin Teaching Hospital (UBTH), a tertiary health institution in Nigeria, was examined over an 18-year period (January 1985 to December 2003). A complete sampling frame was used with all patients' records scrutinized.

Results: A total of 187 patients, (16.6\% of the total ICU admissions) with neurological morbidity were admitted during the period. We observed that morbidity was high for preventable etiologies - head injury (119 patients constituting 63.7\%), tetanus (26 patients constituting 13.9\%), hypertensive encephalopathy (12 patients constituting 6.4\%) and meningitis ( 8 patients constituting $4.8 \%$ ). The case fatality rates for these causes were $50.4 \%, 61.5 \%, 66.7 \%$ and $62.5 \%$ respectively. The case fatality rate for cerebral malaria was $100 \%$. In addition, males $(67.9 \%)$ were more likely to have trauma-related morbidity $(P<.001)$ than females $(32.1 \%)$. Overall mortality rate was high $(52.4 \%)$ and calls for urgent attention.

Conclusion: We concluded that preventable morbidities (head injury, tetanus, meningitis and hypertensive encephalopathy) accounted for fatality among neurological patients in the ICU, Benin City, Nigeria. Mortality was higher among those that required significant intensive interventions. Improved public awareness, traffic legislation, prompt emergency medical care and immunization against tetanus and meningitis should reduce morbidity and mortality.
\end{abstract}

Key words: Morbidity, mortality, neurological patients, intensive care unit

\section{Résumé}

Introduction/Objectif: La morbidité et la mortalité des malades neurologiques traités dans le Service de soins intensifs a montré les causes des troubles neurologiques et l'efficacité de la prise en charge.

Méthodes: La tendance de la morbidité et de la mortalité des malades neurologiques admis dans le service des soins intensifs du centre hospitalier universitaire du Benin (CHUB), un centre de la sente tertiaire au Nigeria, a été étudié au cours d'une période de 10 ans (janvier 1985 au décembre 2003). Un plan de sondage complet a été utilisé avec tous les dossiers des patients étudiés.

Résultats: Un total de 187 patients, (16,6\% du total des admissions ICU) atteints de la morbidité neurologique ont été admis au cours de la période. Nous avons noté que le taux de la morbidité est élevé pour les étiologies évitables - blessures de tête (119 patients recensés en 63,7\%); le tétanos (26 malades recensés en 13,9\%); hypertension encéphalopathie (12 malades recensés en $6,4 \%)$ et la méningite ( 8 malades recensés en $4,8 \%$ ) ; Le taux du cas de la fatalité pour ces causes étaient $50,4 \%, 61,5 \%, 66,7 \%$ et $62,5 \%$ respectivement. Le taux du cas de la fatalité pour la fièvre cérébrale était $100 \%$. En outre, sexe masculin $(67,9(\%)$ étaient plus susceptibles d'avoir des traumatismes liés à la morbidité $(\mathrm{p}<0,001)$ que chez le sexe féminin $(32,1 \%)$. Dans l'ensemble, le taux de la mortalité était élevé $(52,4 \%)$ et demande une attention d'urgence.

Conclusion: Nous avons conclu que des morbidités évitables (blessures à la tête, le tétanos, la méningite et hypertendus encéphalopathie) constituaient pour la fatalité parmi des malades neurologiques à ICH, Benin, Nigéria. La mortalité était plus élevée chez ceux que ont besoin d'une intervention intensive significative. Amélioration dans la sensibilisation du publique, la législation sur la circulation rapide, les 
soins médicaux d'urgence et de la vaccination contre le tétanos et la méningite devrait permettre de réduire la morbidité et la mortalité.

Mots clés: Morbidité, mortalité, patients neurologique, service des soins intensifs

\section{Introduction}

The trend in intensive care in recent times in the developed world is toward establishment of more specialized care units such as cardiac, neurological, renal, pediatric and neonatal units. ${ }^{1-3}$ This is to achieve better patient care and improve outcome. In many developing countries such as Egypt ${ }^{4}$ and Nigeria, ${ }^{5}$ this trend also exists to a lesser extent.

Cohort studies on outcome of patients admitted into pediatric intensive care unit, ${ }^{4}$ medical admissions into intensive care units ${ }^{5,6}$ and working practices and outcome in intensive care units (ICU) ${ }^{7}$ have been carried out in African countries. There is paucity of information on the morbidity and mortality patterns of patients with neurological morbidities admitted into the ICU in sub-Saharan Africa.

It is obvious that the trend of morbidities in intensive care units reflects the pattern of diseases in tertiary health facilities with specialized care services. Hence the understanding of the pattern of ICU morbidity and factors associated with mortality will enable proper planning and implementation of strategies to prevent these diseases or disorders. This is particularly relevant in poor resource, developing economy countries like Nigeria, where health care facilities and access to specialized care units are still far below the acceptable standard.

This study examined neurological patients in the ICU of University of Benin Teaching Hospital (UBTH), Benin City, a tertiary health facility in southern Nigeria, with a view to determining morbidity and mortality patterns and factors that contribute to mortality. In other words, it was essentially designed to give insight to the pattern of neurological morbidities and the accompanying mortality with the objectives of drawing attention to the common etiologies of severe neurological diseases in our setting and the impact of ICU interventions.

\section{Materials and Methods}

This is an 18-year retrospective study from January 1985 to December 2003. Complete sampling of all patients with neurological morbidities admitted into the ICU in UBTH was employed by looking at the master registers and patients' daily records. The case notes, where available, were also examined. Records of patients' demographic characteristics, admission diagnosis, working practices ie, day-to-day living practices, intensive care interventions and monitoring for Therapeutic Intervention Scoring System (TISS) grading was done (appendix 1). TISS grading of patients was made based on active treatment, personnel intensive ICU monitoring, technology intensive ICU monitoring and standard care.
TISS which is a scoring scale for each 36 item in the above major categories, with a maximum score of 78, was determined as TISS class IV for patients who scored 40 points and above, III for patients who scored $20-39$ points, II for patients who scored $10-19$ points and class I for patients who scored less than 10 points. Patients were categorized into TISS class I to IV based on the interventions enumerated below. Four point interventions include cardiac arrest and resuscitation and/or counter-shock within past 48 hours, controlled ventilation with or without PEEP, controlled ventilation with intermittent muscle relaxants, emergency operative procedures within past 24 hours, vasoactive drug infusion $(>1$ drug) and patients needing referral to other tertiary centers with neurosurgical unit and functional neuroimaging facilities.

Three point interventions include assisted ventilation, nasotracheal or orotracheal intubation, blind intra-tracheal suctioning, frequent infusion of blood, bolus intravenous medication (non-scheduled), vaso-active drug infusion (1 drug), active diuresis, coverage with more than two antibiotics, treatment of seizures or metabolic encephalopathy within 48 hours of onset, active treatment of alkalosis and acidosis while two point interventions include central venous pressure line, two peripheral intravenous catheters, fresh tracheostomy (less than 48 hours) and spontaneous respiration via endotracheal tube or $\mathrm{T}$ piece, gastro-intestinal feedings, hourly neuro-vital signs and multiple dressing changes. And one point interventions include electrocardiographic (ECG) monitoring, hourly vital signs, one peripheral IV catheter, standard intake and output every 24 hours, stat blood tests, intermittent scheduled IV medications, routine dressing changes, tracheostomy care, decubitus ulcer, urinary catheter, supplemental oxygen (nasal or mask), IV antibiotics (2 or less), chest physiotherapy, debridement of wounds and gastro-intestinal decompression. The implication of the TISS is that patients who were severely ill belonged to a higher TISS class with greater need for the most interventions and were more likely to die.

The duration of stay in the ICU and outcome were obtained. The case fatality rate was determined by the percentage of the total number of patients diagnosed as having a specific disease who die as a result of the disease within a given period. Mortality rate was calculated as the percentage of the total number of deaths to the total number of neurological patients admitted during the study period. The data are presented as frequency in percentages, medians or means $\pm \mathrm{SD}$. The relative risks and Fischer's exact test were calculated to assess the significant factors contributing to mortality. Categorical data was analyzed using the chi square test where appropriate and the level of significance was taken as $P<.05$. 


\section{Results}

A total of 1124 patients were admitted into the hospital's ICU during the 18-year-period and 187 patients constituting $16.6 \%$ had neurological morbidities. This latter group consisted of 127 $(67.9 \%)$ males and $60(32.1 \%)$ females (Table 1$)$. The mean age of the patients was $25.4 \pm 14.4$ years. The duration of stay of patients in the unit ranged from one to 63 days with a mean of $7.33 \pm 3.41$ days. Majority of the patients $(67.4 \%)$ stayed in the ICU for a week.

The morbidity pattern showed that those with head injury were in the majority $(63.7 \%)$. This was followed by patients with severe tetanus (13.9\%), hypertensive and hypoxic encephalopathy (6.4\%), meningitis $(4.8 \%)$, status epilepticus $(3.2 \%)$, spinalcord injury $(3.2 \%)$, cerebral malaria $(1.3 \%)$ and others as indicated in Table 2. Male patients were more likely to have trauma related neurological morbidity than female patients $(P<.001)$ (Table 2$)$. All the patients with cerebral malaria, cerebral abscess and metabolic encephalopathies were females.

Data on working practices among patients with head injury and tetanus showed that they had anti-tetanus serum and/or tetanus toxoid injection as appropriate in a chemist or other hospital prior to presentation. It was also found that head injury followed trauma and tetanus mainly followed nail puncture wounds, and meningitis occurred in patients who had traveled recently to endemic areas. The patients with meningitis had no prior immunization as it was not a routine vaccine in the southern part of Nigeria.

The overall mortality rate was $52.4 \%$ with 86 $(87.8 \%)$ of the 98 deaths occurring within the first week of ICU admission (Table 3). Mortality rates were significant for all cases with the exceptions of status epilepticus, spinal cord injuries and GuillareBarre syndrome. Cerebral malaria recorded the highest case fatality rate of $100 \%$ though there were just two cases. Majority of the mortality among patients with trauma-related injury (head and spinal cord injury, tetanus) were in the $16-25$ years age group.

Mortality was directly related to severity of illness as the most critically ill patients that needed the most intervention died (Fisher exact test, $P<.0001$, Table 4). Using the Therapeutic Intervention Scoring System (TISS), the Class IV patients (42.8\%) were four times more likely to die compared to those in TISS Classes 1 to $3(\mathrm{RR}=4.01 ; 95 \% \mathrm{CI}=2.45-$ $6.55)$. Gender adjusted mortality rates for males and females were $37 \%$ and $14 \%$ respectively (Fisher exact test $P=.273 ; P>.05, \mathrm{RR}=0.824 ; 95 \% \mathrm{CI}=0.612-$ 1.11).

Table 1. Age and Sex distribution of patients with neurological morbidity admitted into the ICU

\begin{tabular}{llll}
\hline Age (years) & Males (\%) & Females (\%) & Total (\%) \\
\hline $0-5$ & $7(3.7)$ & $3(1.6)$ & $10(5.4)$ \\
$6-15$ & $27(14.4)$ & $10(5.4)$ & $37(19.8)$ \\
$16-25$ & $25(13.4)$ & $13(6.9)$ & $38(20.3)$ \\
$26-35$ & $25(13.4)$ & $12(6.4)$ & $37(19.8)$ \\
$36-45$ & $16(8.6)$ & $6(3.2)$ & $22(11.8)$ \\
$46-55$ & $12(6.4)$ & $6(3.2)$ & $18(9.6)$ \\
$56-65$ & $10(5.4)$ & $7(3.7)$ & $17(9.1)$ \\
$66-75$ & $3(1.6)$ & $1(0.5)$ & $4(2.1)$ \\
$76-85$ & $2(1.1)$ & $2(1.1)$ & $4(2.1)$ \\
\hline Total & $\mathbf{1 2 7}(\mathbf{6 8})$ & $\mathbf{6 0}(\mathbf{3 2})$ & $\mathbf{1 8 7}(\mathbf{1 0 0})$ \\
\hline
\end{tabular}

Table 2. Morbidity Pattern of Neurological Patients in the ICU

\begin{tabular}{llll}
\hline Diagnosis & Males (\%) & Females (\%) & Total (\%) \\
\hline Head injury / increased ICP & $94(50)$ & $25(13.3)$ & $119(63.3)$ \\
Spinal cord injury & $5(2.7)$ & $1(0.5)$ & $6(3.2)$ \\
Severe Tetanus with respiratory failure. & $19(10.1)$ & $7(3.7)$ & $26(13.8)$ \\
Meningitis & $5(2.7)$ & $3(1.6)$ & $8(4.3)$ \\
Status Epileptic us & $2(1.1)$ & $4(2.1)$ & $6(3.2)$ \\
Hypertensive Encephalopathy (One Hypoxic included) & $2(1.1)$ & $10(5.3)$ & $12(6.4)$ \\
Guillaine- Barre syndrome & $1(0.5)$ & $2(1.1)$ & $3(1.6)$ \\
Cerebral Malaria & - & $2(1.1)$ & $2(1.1)$ \\
Cerebral Abscess & - & $2(1.1)$ & $2(1.1)$ \\
Coma? (Unidentifiable etiology) & - & $2(1.1)$ & $2(1.1)$ \\
Acute Organic Brain Syndrome & - & $2(1.1)$ & $2(1.1)$ \\
\hline Total & $* \mathbf{1 2 8}(\mathbf{6 8 . 2 )}$ & $\mathbf{6 0 ( 3 1 . 8 )}$ & $\mathbf{1 8 8 * ( 1 0 0 )}$ \\
\hline *One patient with head injury had tetanus & & & \\
ICP: Intracranial pressure & & &
\end{tabular}


Table 3. Outcome pattern in ICU patients with neurological morbidity

\begin{tabular}{|c|c|c|c|}
\hline \multirow[t]{2}{*}{ Diagnosis } & \multirow{2}{*}{$\begin{array}{l}\text { Total Number of } \\
\text { Patients }(\%)\end{array}$} & \multicolumn{2}{|l|}{ Outcome (\%) } \\
\hline & & Patients who Survived & Patients who died \\
\hline Head injury & $119(63.3)$ & $59(31.5)$ & $60(31.8)$ \\
\hline Severe Tetanus & $26(13.8)$ & $10(5.3)$ & $16(8.5)$ \\
\hline Meningitis & $8(4.3)$ & $3(1.6)$ & $5(2.7)$ \\
\hline Status Epileptic us & $6(3.2)$ & $5(2.7)$ & $1(0.5)$ \\
\hline Hypertensive Encephalopathy & $12(6.4)$ & $4(2.1)$ & $8(4.3)$ \\
\hline Spinal Cord injury & $6(3.2)$ & $4(2.1)$ & $2(1.1)$ \\
\hline Guillaine- Barre Syndrome & $3(1.6)$ & $2(1.1)$ & $1(0.5)$ \\
\hline Cerebral Malaria & $2(1.1)$ & - & $2(1.1)$ \\
\hline Cerebral Abscess & $2(1.1)$ & $1(0.5)$ & $1(0.5)$ \\
\hline Coma ? (Unidentifiable etiology) & $2(1.1)$ & $1(0.5)$ & $1(0.5)$ \\
\hline Acute Organic Brain Syndrome & $2(1.1)$ & $1(0.5)$ & $1(0.5)$ \\
\hline Total & * $188(100)$ & $90(47.9)$ & * $98(52.1)$ \\
\hline
\end{tabular}

Table 4. Mortality as it relates to severity of illness of neurological patients in the ICU

\begin{tabular}{|c|c|c|c|}
\hline $\begin{array}{l}\text { Class of } \\
* \text { TISS }\end{array}$ & No. of patients who Survived & No. of patients who Died & Total \\
\hline I & 9 & - & 9 \\
\hline II & 38 & 7 & 45 \\
\hline III & 28 & 25 & 53 \\
\hline IV & 14 & 66 & 80 \\
\hline Total & 89 & 98 & 187 \\
\hline
\end{tabular}

\section{Discussion}

Neurological disorders accounted for between $65 \%$ and $71.6 \%{ }^{8,9}$ of the morbidities in intensive care units, though there are reports with lower rates ${ }^{1}$ corroborating the rate observed in this study.

In this study, morbidity pattern of our neurological patients was found to be mainly due to preventable causes such as head injury, tetanus, hypertensive encephalopathy and meningitis. Head injury and tetanus were found to be trauma related in our study. In the United States, trauma is the fourth leading cause of death among intensive care patients. ${ }^{8}$ In Nigeria, although specific figures for causes of death are unknown, trauma still ranks high. ${ }^{10}$ In this study, tetanus was the second most common cause of ICU admissions during the period. This contrasts with the reports from Lagos, Nigeria, where tetanus accounted for most of the ICU admissions. ${ }^{9}$ Tetanus resulted from nail puncture wounds in most of the patients and this has been reported by other authors. ${ }^{11}$ Meningitis was associated with travels to areas highly endemic for this disease. This contrasts with appraisals in the literature for developed countries where abortions accounted for sources of tetanus managed in the $\mathrm{ICU}^{12}$ and neuraxial blocks for meningitis. ${ }^{13}$ For trauma related morbidities namely, head injury and tetanus, majority of the patients were in 16-25 years age group representing the highly productive and actively mobile sector of the population with increased risk of trauma. In addition, a significant number of male patients had trauma related morbidities probably due to the relationship between masculine identity and risk taking. The literature is replete with reports of cases of status epilepticus, $^{14}$ Guillaine Barre syndrome $^{15}$ and encephalopathy ${ }^{16}$ admitted into the ICU but these disorders were not common among our intensive care patients.

The high overall mortality rate recorded in this study could be as a result of the severity of illness on admission to the ICU (42.8\% of neurological patients belonged to TISS class IV), inadequate facilities to guide necessary therapeutic interventions such as extradural intracranial pressure monitor, availability of functional neuro-imaging facilities and the absence of a neurosurgical unit. The presence of a specialized neurocritical care team has been reported to reduce in-hospital mortality and length of stay in ICU. ${ }^{17}$ Another contributing factor to mortality is nonneurologic organ dysfunction in patients with brain injury and this has been identified as an independent predictor of poor outcome. This dysfunction may arise as a result of the neurologic injury or secondary to treatment. $^{18}$

The mortality rate of $61.5 \%$ found among tetanus patients is consistent with the range reported in four African countries including Nigeria in $1995 .^{19}$ However, Oke et $a l^{5}$ reported the least mortality rate (5.3\%) among tetanus patients in Lagos University Teaching Hospital Nigeria in 2001 as against a mortality rate of $45.5 \%$ reported in 1991 in the 
same center. $^{20}$ It should be emphasized that immunisation against tetanus and meningitis in adults is limited to when an injury is being treated in a health institution and when there is a need to travel out of the country as required by legislation respectively. This results in poor immunization coverage of the population.

The high case fatality rates for preventable morbidities found in the study is worrisome as these diseases are easily preventable through vaccination (tetanus, meningitis), malaria prophylaxis (cerebral malaria), and control of hypertension with appropriate drugs. Health care providers should therefore be enlightened about the need for routine tetanus immunization rather than only following injury and the use of a less antigenic alternative, the human tetanus immunoglobulin (HTIG) in 500 international units single intramuscular dose for passive immunity for injuries over 24 hours. ${ }^{21}$ Strict traffic legislation and its implementation will go a long way in preventing automobile accidents and resultant head and spinal injuries. ${ }^{1,8}$

\section{Conclusion}

This study revealed that head injury, tetanus, meningitis, hypertensive encephalopathy and cerebral malaria were the leading causes of death among neurological patients in Benin City, Nigeria. It also showed that causes of neurological morbidity are preventable and had high case fatality rates. We recommend health education of the public to improve awareness on adequate immunisation, appropriate drug management including anti malaria prophylaxis and antihypertensive therapy. There is also a need for improved enforcement of appropriate traffic legislation such as wearing of seat belts to reduce head and spinal cord injuries. The establishment of a neurosurgical unit with provision of appropriate monitors for efficient care will improve the outcome of these patients.

\section{References}

1. Cohen A, Bodenham A, Webster N. A review of 2000 consecutive ICU admissions. Anaesthesia. 1993;48:106-110.

2. Dobb GJ. Pediatric Intensive Care (editorial) Int. Care World 1993; 10; 4:165.

3. Arunodaya GR. Infections in neurology and neurosurgery in Intensive Care Units. Neurol India. 2001;49(Suppl 1):551-559.

4. El-Nawawy A. Evaluation of outcome of patients admitted to the pediatric intensive care unit in Alexandria using the pediatric risk of mortality (PRISM) score. J Trop Pediatr. 2003;49:109-114.

5. Oke DA. Medical admissions into the Intensive care Unit of Lagos University Teaching Hospital. Niger Postgrad Med J. 2001;8:178-182.

6. Hesse IF, Mensah A, Asante DK, et al. Characteristics of adult tetanus in Accra. West Afr J Med. 2003;22:291-294.
7. Adudu OP, Adudu OG. Working practices and patients' outcome in the Intensive care unit of the University of Benin Teaching Hospital. JMBR. 2004;3:67-72.

8. Stene JK, Grande CM. Anaesthesia for trauma. In: Cucchiara R.F., Miller, (Jr.) E.D., Reeves J.G, Roizen M.F. Savarese J.J. (Eds). Anaesthesia, 4th edition, New York: Churchill Livingstone 1994; 2:2157- 173 .

9. ffoulkes - Crabbe DJO. The Intensive Care Unit of the Lagos University Teaching Hospital - An Anesthetist's experience. Niger Med J. 1977;7:50-56.

10. Elechi EN, Etawo SU. Pilot study of injured patients seen in University of Port Harcourt Teaching Hospital, Nigeria. Injury. 1990;21:234238.

11. Ogunrin OA, Unuigbe EI. Tetanus: An analysis of the prognosticating Factors of cases admitted into the medical wards of a tertiary hospital in a developing African country between 1990 and 2000. Niger Postgrad Med J. 2004;11:97-102.

12. Siguier FB, Etourne C, Kahn MF. Fatal tetanus during caesarean section, seven months after a tentative unsuccessful abortion (article in French). Bull Mem Soc Med Hop Paris. 1958;74:179-181.

13. De Tommaso O, Caporuscio A, Tagriello V. Neurological complications following central neuraxial blocks: Are there predictive factors [review]. Eur J Anaesthesiol. 2002;19:705-716.

14. Outin H, Liot $\mathrm{P}$, Jonghe $\mathrm{B}$, Thomas $\mathrm{P}$. Management of adult refractory convulsive status epilepticus in the Intensive Care Unit. Neurology. 2002;59:1249-1251.

15. Kapil D, Bagga A. The profile and outcome of patients admitted to a paediatric intensive care unit. Indian J Pediatr. 1993;60:5-10.

16. Wijdicks EFM. Neurological complications in critically ill patients [review]. Anesth Analg. 1996;83:411-419.

17. Suarez JI, Zaidat OO, Suri MF, et al. Length of stay and mortality in neurocritically ill patients: impact of a specialized neurocritical care team. Crit Care Med. 2004;32:2363-2364.

18. Zygun D. Non-neurological organ dysfunction in neurocritical care: impact on outcome and etiological considerations. Curr Opin Crit Care. 2005;11:1339-1343.

19. Petit PL, Van Ginneken JK. Analysis of hospital records in four African countries 1975 - 1990 with emphasis on infectious diseases. J Trop Med Hyg. 1995;98:217-227.

20. Bandele EO, Akinyanju OO, Bojuwoye BJ. An analysis of tetanus deaths in Lagos. J Natl Med Assoc. 1991;83:55-58.

21. Pascual FB, McGinley EL, Zanardi LR, et al. Tetanus Surveillance- United States, 1998-2000. MMWR Surveillance. 2003;52:1-8. 
Appendix 1. Therapeutic intervention scoring system

\begin{tabular}{|c|c|}
\hline Interventions & Points \\
\hline \multicolumn{2}{|l|}{4 - point interventions } \\
\hline 1. Cardiac arrest and resuscitation (and/or counter-shock within past $48 \mathrm{~h}$ ) & 4 \\
\hline 2. Controlled ventilation with or without PEEP & 4 \\
\hline 3. Controlled ventilation with intermittent muscle relaxants & 4 \\
\hline 4. Emergency operative procedures within past $24 \mathrm{~h}$ & 4 \\
\hline 5. Vaso-active drug infusion ( $>1$ drug) & 4 \\
\hline $\begin{array}{l}\text { 6. Referral to other tertiary centers with neurosurgical unit and functional neuro-imaging } \\
\text { facilities }\end{array}$ & 4 \\
\hline \multicolumn{2}{|l|}{3 - point interventions } \\
\hline 1. Assisted ventilation & 3 \\
\hline 2. Nasotracheal or orotracheal intubation & 3 \\
\hline 3. Blind intra-tracheal suctioning & 3 \\
\hline 4. Frequent infusion of blood and bolus intravenous medication (non-scheduled) & 3 \\
\hline 5. Vaso-active drug infusion (1 drug) & 3 \\
\hline 6. Active diuresis & 3 \\
\hline 7. Coverage with more than two antibiotics & 3 \\
\hline 8. Treatment of seizures or metabolic encephalopathy within $48 \mathrm{~h}$ of onset & 3 \\
\hline 9. Active treatment of alkalosis and acidosis & 3 \\
\hline \multicolumn{2}{|l|}{ 2-point interventions } \\
\hline 1. Central venous pressure line & 2 \\
\hline 2. Two peripheral intravenous catheters & 2 \\
\hline $\begin{array}{l}\text { 3. Fresh tracheostomy (less than } 48 \mathrm{~h} \text { ) and spontaneous respiration via endotracheal tube or } \mathrm{T} \text { - } \\
\text { piece }\end{array}$ & 2 \\
\hline 4. gastro-intestinal feedings & 2 \\
\hline 5. hourly neuro-vital signs & 2 \\
\hline 6. multiple dressing changes & 2 \\
\hline \multicolumn{2}{|l|}{1 - point interventions } \\
\hline 1. Electrocardiographic (ECG) monitoring & 1 \\
\hline 2. Hourly vital signs & 1 \\
\hline 3. One peripheral IV catheter & 1 \\
\hline 4. Standard intake and output every $24 \mathrm{~h}$ & 1 \\
\hline 5. Stat blood tests & 1 \\
\hline 6. Intermittent scheduled IV medications & 1 \\
\hline 7. Routine dressing changes & 1 \\
\hline 8. Tracheostomy care & 1 \\
\hline 9. Decubitus ulcer & 1 \\
\hline 10. Urinary catheter & 1 \\
\hline 11. Supplemental oxygen (nasal or mask) & 1 \\
\hline 12. IV antibiotics ( 2 or less) & 1 \\
\hline 13. Chest physiotherapy & 1 \\
\hline 14. Debridement of wounds & 1 \\
\hline 15. Gastro-intestinal decompression & 1 \\
\hline
\end{tabular}

